\title{
O PAPEL DA EDUCAÇÃO ESCOLAR NA VIDA DE UM ADOLES- CENTE AUTOR DE ATO INFRACIONAL: um estudo de caso ${ }^{1}$
}

\author{
THE EDUCATION ROLE IN THE LIFE OF A TEENAGER WHO IS AUTHOR OF AN \\ INFRACTIONAL ACT: a case study
}

EL PAPEL DE LA EDUCACIÓN EN LA VIDA DE UN ADOLESCENTE QUE COME-
TE UNA INFRACCIÓN: un estudio de caso

Marcos Vinicius Francisco Professor Doutor da Universidade do Oeste Paulista (UNOESTE). Presidente Prudente - SP, Brasil. marcos_educa01@yahoo.com.br

Camélia Santina Murgo Professora Doutora da Universidade do Oeste Paulista (UNOESTE). Presidente Prudente - SP, Brasil. camelia@unoeste.br

RESUMO: Desenvolveu-se esta pesquisa em uma escola de Ensino Fundamental e Médio de uma cidade do interior do estado de São Paulo. Assumiu-se como objetivo analisar o papel da educação escolar na vida de um adolescente autor de ato infracional que cumpriu medida socioeducativa de internação. Neste estudo de caso, assumiu-se como referencial a Teoria Histórico-Cultural que tem como base epistemológica o Materialismo Histórico-Dialético. Realizaram-se entrevistas semiestruturadas com o adolescente, análise de seu desempenho escolar e grupos focais com seus professores e a coordenadora da escola. No que tange à inserção escolar do adolescente, constatou-se um movimento de ambivalência com relação às instituições por onde ele passou. Nesse processo, reconhece-se a importância da escola atual, que ao recebê-lo, após o período de internação adotou uma postura de acolhida, assumindo a dimensão afetiva como central na relação professor-aluno. A dinâmica institucional foi positiva ao fazer com que o adolescente se sentisse confiante e percebesse a necessidade de terminar os estudos, almejando obter futura inserção profissional e o ingresso na universidade. PALAVRAS-CHAVE: Ato infracional. Educação escolar. Adolescente.

ABSTRACT: This research was developed in an elementary and high education school in a country town of São Paulo State. It is assumed as objective to analyze the role of school education in the life of a teenager who has committed an infractional act and has fulfilled the socio-educational measure of internment. In this case study, it was assumed as reference the Historical-Cultural Theory whose epistemological basis is the Historical-Dialectical Materialism. Were carried out semi-structured interviews with the teen, analysis of his school performance and focus groups with his teachers and the school coordinator. Regarding the school insertion of the adolescent, it was found an ambivalence movement in relation to the institutions where he went. In this process, it is recognized the importance of the current school, which when received him after the internment period, adopted an attitude of welcome, assuming the affective dimension as central in the teacher-student relationship. The institutional dynamic was positive by making the teen feel confident and realize the need to finish school, aiming to obtain future occupational integration and entry into the university. KEYWORDS: Infractional Act. Scholar education. Teenager.

RESUMEN: Esta investigación se desarrolló en una escuela de primaria y secundaria en una ciudad en el estado de Sao Paulo. Se asume como objetivo analizar el papel de la educación en la vida de un adolescente que cometió un acto de infracción y que ha cumplido medida socioeducativa de internamiento. En este estudio de caso, se asumió como referencia la Teoría Histórico-Cultural cuya base epistemológico es el Materialismo Histórico y Dialéctico. Hubo entrevistas semiestructuradas con el adolescente, el análisis del rendimiento escolar y grupos de discusión con sus profesores y el coordinador de la escuela. Com respecto a la inserción escolar de lo adolescente, se observó un movimiento de ambivalencia con relación a las instituciones donde estudió. En el proceso, se reconoce la importancia de la escuela actual, en recibirlo después del período de internamiento; la escuela adoptó una actitud de bienvenida, teniendo la dimensión afectiva como elemento central de la relación profesor-alumno. La dinámica institucional fue positiva, el adolescente ha sentido confianza a darse cuenta de la necesidad de terminar la escuela, con el objetivo de obtener una futura integración profesional además de la entrada en la universidad.

PALABRAS CLAVE: Ley infracional. Educación escolar. Adolescente.

${ }^{1}$ Pesquisa financiada pela Coordenação de Aperfeiçoamento de Pessoal de Nível Superior (CAPES).

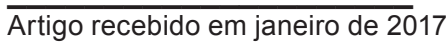

Aprovado em março de 2017 
O PAPEL DA EDUCAÇÃO | Marcos Vinicius Francisco e Camélia Santina Murgo

\section{1| INTRODUÇÃO}

Embora o Estatuto da Criança e do Adolescente (ECA) compreenda a adolescência como o período entre os 12 e 18 anos de idade, a concepção assumida nesta investigação ultrapassa qualquer tipo de visão universalista. Tal como Castro e Guareschi (2008), Coelho e Rosa (2013) e Vygotsky (1995), entende-se que a adolescência é construída a partir da realidade social e histórica na qual um indivíduo encontra-se inserido.

Leontiev (1983) aponta que o homem é um ser social que nasce com necessidades biológicas e que elas serão satisfeitas através da mediação de outros indivíduos. No atual modelo de sociedade, o capitalista, as pessoas estão em relações opostas aos meios de produção e ao produto social. Na maioria dos casos, o que os homens produzem está acessível a uma minoria da população.

Muitos adolescentes à margem do processo de apropriação dos bens materiais e culturais produzidos pela humanidade acabam se envolvendo em atos infracionais. Impera a lógica de um Estado que não é capaz de oferecer políticas públicas de inserção social e proteção para essa parcela da população. Muitos, por exemplo, são aliciados pelo crime organizado/tráfico de drogas, em troca de dinheiro. A exclusão econômica ultrapassa o impedimento ao consumo lançado pelo capitalismo (CASTRO; GUARESCHI, 2008).

Conforme Brasil (1990, p. 42), art. 103, "considera-se ato infracional a conduta descrita como crime ou contravenção penal." Para o art. 104 "são penalmente imputáveis os menores de 18 anos sujeitos às medidas previstas." Para efeitos de esclarecimento, o inciso VII prevê medidas especiais de proteção que podem levar em consideração as necessidades pedagógicas do adolescente, ou àquelas que visam o fortalecimento dos vínculos familiares e comunitários. As medidas de internação em estabelecimento educacional deveriam ser adotadas em casos de excepcionalidade. Contudo, assiste-se a desenfreada aplicação de tal medida pelos juízes (CASTRO; GUARESCHI, 2008; MONDINI, 2011), sem haver um maior entendimento dos impactos que tais medidas poderão ter na vida dos adolescentes. O encarceramento deve ser entendido, apenas, como mais uma forma de controle social dos excluídos no sistema capitalista (FEFFERMANN, 2008; SALDOMBIDE, 2013).

Castro e Guareschi (2008, p. 200) ao se reportarem às instituições de internação de adolescentes autores de atos infracionais ponderam que: "os maus tratos nelas sofridos, as mortes, as superlotações e os preconceitos induzem o senso comum a responsabilizar, especialmente essa parcela da população pelo aumento da violência urbana no país." Paradoxalmente, a juventude brasileira é a parcela da população que mais padece e morre em função de situações de violência.

De modo geral, os adolescentes em conflito com a lei possuem renda familiar baixa; grau de escolaridade não adequado à relação idade/série (BAZON; SILVA; FERRARI, 2013; COELHO; ROSA, 2013; PADOVANI; RISTUM, 2013); residem em locais marcados pela vulnerabilidade social, expressos em subcondições de habitação, saneamento, escolarização e renda familiar. Ganha relevo "a ausência de proteção por parte do Estado, da família e da sociedade" (COELHO; ROSA, 2013, p. 164). Coelho e Rosa (2013) e Silva e Salles (2011) ressaltam, ainda, o quanto o tráfico de drogas vem se consubstanciando como um dos principais fatores que contribuem para o cometimento dos atos infracionais.

Ao analisaremo papel da escola na vida de adolescentes autores de atos infracionais, Silvae Salles (2011) constataram que esta se configura como um espaço ambivalente. Ao mesmo tempo em que denunciam trajetórias de conflitos, marcadas por transferências e expulsões, destacam gostar das

\footnotetext{
${ }^{1} \mathrm{Em}$ alguns momentos do texto, para além do conceito de "adolescentes" utiliza-se o conceito de "jovens", embora se deva reconhecer que eles são distintos. Tal opção justifica-se diante da necessidade de manter nas citações as terminologias utilizadas pelos autores aqui citados.
} 
escolas e reconhecem sua importância, apesar de não terem mencionado estima pelos conteúdos escolares. Os adolescentes apresentam uma visão utilitarista da escola ao relacionarem-na com sua vida futura, frente às possibilidades de conseguirem um bom emprego ou acesso ao ensino superior.

Bazon, Silva e Ferrari (2013) apontam que as escolas devem ser entendidas como uma das instâncias que têm participação significativa na construção das trajetórias de adolescentes envolvidos em delitos. Todavia, apregoam certa prudência, ao passo que pouco se conhece sobre o processo de escolarização dessa parcela da população no Brasil.

Não é qualquer tipo de intervenção que deverá ser realizada na práxis-pedagógica com esses adolescentes. Os professores precisam assumir uma pedagogia específica, metodologias diversificadas, além de uma postura sensível nas relações a serem estabelecidas com esses jovens (PADOVANI; RISTUM, 2013). Diante dessas ponderações, o objetivo central deste artigo foi analisar o papel da educação escolar na vida de um adolescente autor de ato infracional que cumpriu medida socioeducativa de internação.

\section{2 | METODOLOGIA}

A busca pelo método se converte em uma das tarefas mais importantes no processo de investigação das diferentes nuances do conhecimento humano. Na perspectiva da Teoria Histórico-Cultural, que tem como base epistemológica o Materialismo Histórico-Dialético, compreende-se como objetivo da investigação científica "[...] revelar ou por em evidência as relações e os nexos dinâmico-causais que constituem a base de todo o fenômeno" (VYGOTSKY, 1995, p. 101, tradução nossa).

A análise prima pela explicação científica, na busca pela essência do fenômeno. Por conseguinte, o pesquisador deve ultrapassar a aparência imediata e empírica do objeto investigado (PAULO NETTO, 2011; VYGOTSKY, 1995).

\subsection{Seleção da escola}

Num primeiro momento realizou-se um levantamento junto às escolas de um município de médio porte do interior do estado de São Paulo, a fim de descobrir aquelas que recebem adolescentes egressos das diferentes unidades da Fundação Casa do referido estado, autores de atos infracionais e que cumpriram medidas socioeducativas de internação. Identificou-se que os alunos são direcionados maciçamente para uma mesma escola da cidade.

\subsection{Seleção dos participantes}

Em contato com a escola e com as devidas autorizações para a realização da pesquisa, procedeu-se pelo levantamento de alunos egressos da Fundação Casa que se matricularam no ano letivo de 2014 na instituição. Respeitando a identidade dos participantes da investigação, em conformidade com os princípios defendidos pelo Brasil (1990), constatou-se que a escola possuía um total de 26 alunos nessa condição, além de 06 alunos que foram para unidades da Fundação Casa pela primeira vez, sendo todos do sexo masculino.

Desse total, apenas 02 alunos permaneceram cursando regularmente o ano letivo de 2014. Termos de Consentimento Livre Esclarecido (TCLE) foram entregues a eles, bem como aos seus responsáveis para efetivar o consentimento de participação da pesquisa. Posteriormente, na busca dos TCLE, um estudante disse que não gostaria de participar do estudo. Assim, apenas um adolescente aceitou participar da investigação. 
Os professores deste aluno, ou seja, os docentes que lecionavam para o $1^{\circ}$ ano do Ensino Médio, na modalidade de Educação de Jovens e Adultos (EJA), no período noturno, foram convidados a participar de um grupo focal (09 professores). O convite também foi efetuado à coordenadora pedagógica dessa etapa de escolarização. Estabeleceu-se o dia e horário da Aula de Trabalho Pedagógico Coletivo (ATPC) para a realização do grupo focal. Assim, seis professores responsáveis por oito disciplinas, mais a coordenadora pedagógica foram os participantes do grupo focal.

Adotou-se o estudo de caso, na perspectiva da Teoria Histórico-Cultural. Sustenta-se tal preposição a partir de Vygotski (2007), para quem a visão articulada do todo, não se dá exatamente por determinado estudo tratar de um grande número de sujeitos, pois onde há apenas um único ser humano, ali está um ser social.

\subsection{Entrevistas semiestruturadas}

Posteriormente, realizou-se um conjunto de três entrevistas semiestruturadas, com o adolescente, com duração média de 45 minutos cada. As entrevistas foram gravadas, com a intenção de que ele pudesse apresentar em linhas gerais: aspectos sócios demográficos; os motivos que o conduziram ao cometimento do ato infracional; o papel da escola em sua vida; o que pensa da escola da Fundação Casa; o papel das relações interpessoais em sua vida escolar e para além dela; expectativas futuras de vida.

Após a transcrição das entrevistas, elas foram analisadas por meio de eixos analíticos que favoreceram uma maior compreensão do fenômeno investigado.

\subsection{Análise do desempenho escolar}

Com a intenção de abordar mais elementos ligados aos impactos da educação escolar na vida do adolescente, procedeu-se pelo levantamento de seu desempenho escolar. Adotou-se como foco de análise o boletim escolar do segundo semestre de 2014, período referente ao $1^{\circ}$ ano do Ensino Médio da Educação de Jovens e Adultos.

\subsection{Grupo focal}

Foram realizadas duas sessões de grupos focais, cada uma contendo duração de aproximadamente uma hora. Conforme Gatti (2005), o grupo focal foi adaptado como técnica de pesquisa à investigação científica em Ciências Sociais e Humanas, em especial, a partir da década de 1980. A autora destaca a importância de que os participantes tenham vivência com o tema a ser investigado. Por isso, nesta investigação, adotou-se a seleção de professores que tinham contato com o aluno que cometeu atos infracionais e que cumpriu medidas socioeducativas. Gatti (2005) ressalta, ainda, que os grupos focais representam uma possibilidade efetiva de troca e diálogo entre os participantes de uma pesquisa.

As questões que balizaram o grupo foram: $O$ que pensam sobre a inserção de adolescentes autores de atos infracionais que cumpriram medidas socioeducativas de internação no sistema regular de ensino? Quais as práticas adotadas pela escola e em sua práxis-pedagógica quando diante de alunos autores de atos infracionais? Como se relacionam com eles? Todas as falas foram gravadas em um aparelho digital. Após as transcrições, optou-se por selecionar algumas respostas, na intenção de agregá-las as análises decorrentes das entrevistas com o participante. 


\section{3 | ANÁLISE E DISCUSSÃO DO ESTUDO DE CASO}

Leandro (nome fictício), 18 anos, nasceu e cresceu no mesmo bairro que reside atualmente. O bairro está localizado em uma região de média exclusão, de acordo com o Mapa da Exclusão Social do município onde a pesquisa foi realizada (CAMACHO, 2013). Do ponto de vista territorial o bairro é afastado do tecido urbano, sendo marcado pela baixa mobilidade social. Os indivíduos nessas áreas geralmente são apartados do todo social, tendo em vista que as dificuldades de transporte, as distâncias em relação ao local de trabalho concernem a certa imobilidade e impedem maior interação com o resto da cidade (SILVA, 2009).

O participante vive com sua mãe (35 anos), padrasto (28 anos) e duas irmãs mais novas (07 e 06 anos de idade), filhas do casal. Essa família foi formada há 12 anos, quando Leandro tinha 05 anos. À época da pesquisa a mãe encontrava-se desempregada e o padrasto com o trabalho de pintor era o responsável pelo sustento da família.

Nesse contexto, as possibilidades de apropriação das diferentes manifestações materiais e culturais, produzidas pelo gênero humano foram escassas e precárias. Esse cenário, conforme relato do participante, o conduziu à inserção no mundo do crime, via tráfico de drogas, a fim de obter recursos financeiros, roupas e acessórios difundidos fortemente nos meios de comunicação.

\subsection{Trajetórias escolares do adolescente autor de ato infracional}

Ao analisar o papel da educação escolar na vida de Leandro (todas as falas presentes nessa seção são do referido participante), constata-se que o primeiro ciclo do ensino fundamental foi cursado na escola do bairro onde reside. O carinho por essa escola ficou expresso nos grandes vínculos de amizades construídos.

Ah minha familia né, família, porque querendo ou não ali todo mundo criou amizades. Os meus amigos de hoje, a maioria deles posso dizer que começou desde ali [...] (Participante da pesquisa).

Evidenciou-se também que nessa época Leandro não apresentava envolvimento com o tráfico de drogas. Em sua percepção a escola era organizada, mesmo diante das travessuras feitas pelos estudantes, além de conter professores que os respeitavam.

A gente deixava de cabeça para baixo, porque era criança né, fazíamos bagunça pra caramba! Depois tinha os funcionários que arrumavam tudo e deixavam tudo certinho para o dia seguinte [...] Todos os professores que eu tive nunca me ofenderam ou ofenderam alguém. (Participante da pesquisa).

Como exemplo de uma professora que lhe deixou marcas positivas nessa fase de escolarização, mencionou sua professora da $4^{\mathrm{a}}$ série (atual $5^{\circ}$ ano do Ensino Fundamental):

Eu me lembro de uma quando eu estava na $4^{a}$ série e teve um concurso na escola da melhor frase para a mãe, aí eu fui para casa e levei um papel para preencher e enviar para eles e concorrer para ganhar um diploma, para nós isso era tudo naquela época! Um diplominha falando que ganhou a frase. Aí eu fiz [...] e minha mãe me ajudou [...] Depois a professora falou parabéns Leandro, ela ficou feliz que eu consegui, ela se chama professora Renata, até hoje eu me lembro dela. Quando eu a vejo ela me cumprimenta [...] Ela sempre foi uma boa professora! Boa porque sempre soube lidar com a gente, nunca maltratou a gente. Foi uma pessoa boa, que sabia lidar com crianças. (Participante da pesquisa).

Bazon, Silva e Ferrari (2013, p. 175) indicam a existência de duas trajetórias de escolarização entre os adolescentes em conflitos com a lei. Uma é marcada "pela descontinuidade na qualidade das vivências escolares, com um período inicial positivo, que se torna negativo em seguida; e outro, cuja marca é a continuidade preponderantemente negativa da experiência, desde o início." 
Na investigação conduzida por esses pesquisadores a primeira trajetória se fez mais presente entre os participantes. Há que se ressaltar movimento similar no processo de escolarização de Leandro, sobretudo, até o momento no qual ele foi conduzido ao regime de internação junto à Fundação Casa.

Após o término do Ensino Fundamental I, Leandro e seus colegas de escola foram realocados para uma escola em um bairro próximo que oferecia o Ensino Fundamental II ( $6^{\circ}$ ao $9^{\circ}$ ano). Lá suas experiências escolares foram negativas, ele foi reprovado quatro anos consecutivos na antiga $8^{a}$ série (atual $9^{\circ}$ ano do Ensino Fundamental).

Sobre as reprovas escolares, Bazon, Silva e Ferrari (2013) ressaltam que o afastamento da escola, seja por expulsão ou por formas sutis de exclusão (baixo desempenho, relação conflituosa entre professores e alunos e clima escolar ruim etc.), configuram-se como fortes indicadores para a entrada ou para o agravamento da conduta delituosa. Para além das reprovas, Leandro destacou uma relação conturbada com a maioria de seus professores.

Aquela escola tem muito que melhorar. Porque os professores, às vezes, não são bons, são mal educados [...] Sabem dar o ensinamento para os alunos, mas não sabem lidar com o serviço e com a família, ou seja, do serviço para com a família e da família para o serviço. Aí complica né?[...] Ficam nervosos no serviço, ficam alterados, falam meio alto e começam a falar mais grosso com as outras pessoas. (Participante da pesquisa).

A pesquisa desenvolvida por Coelho e Rosa (2013) junto a um grupo de adolescentes em conflito com a lei, caracterizados de acordo com condições de vida vulneráveis, trouxe à tona a denúncia de alguns aspectos presentes na educação formal. As escolas mencionadas eram precárias e apresentavam professores pouco capacitados.

Há que se ponderar que por trás dessa denúncia, embora os professores façam parte do sistema educacional, não há a intenção de culpabilizá-los ou de responsabilizá-los pelo atual cenário da educação escolar, visto que conforme Bruno (2011, p. 553), "a educação deixou de ser uma questão nacional e passou a ser, planejada e regulada por centros de poder que vão muito além dos Estados Nacionais." No Brasil, por exemplo, a educação vem se subordinando as exigências firmadas por meio de acordos multilaterais com as agências regulatórias a serviço do capital, tais como o Fundo Monetário Internacional (FMI), Banco Mundial (BM) e Organização Mundial de Comércio (OMC) (HADDAD, 2008).

Nessa lógica, sob o ponto de vista do capital, seria desnecessário e oneroso educar a totalidade das novas gerações num mesmo grau de complexidade, pois frente à dinâmica do mercado de trabalho formal, totalmente estratificado e seletivo, muitos jovens sequer serão inseridos nele. Eles comporão o chamado exército de reserva ou executarão trabalhos simples que não exigirão o mesmo grau de complexidade e inovação (BRUNO, 2011).

Assume-se, então, a partir de Bruno (2011), que a educação vem sendo associada à produção de capacidade de trabalho, embora, nem todos os jovens serão totalmente contemplados nesse processo, aliado ao fato de ser um mecanismo de controle social. O que se nomeia como degradação do ensino, no Brasil, decorre da dificuldade em se alcançar ganhos de produtividade na forma atual de organização dos processos de ensino, ao passo que tem se recorrido a uma redução de custos. A própria formação de professores aderiu a essa lógica, embora diante do aumento da escolaridade.

Tal problemática desencadeia ou tras prerrogativas, já que os professores, na atualidade, são solicitados a atuar como mediadores entre os estudantes e os diferentes níveis de administração que representam o poder. Sua autoridade e identidade profissional estão cada vez mais fragilizadas pelas novas formas de gestão que Ihes oblitera a iniciativa e autonomia, frente aos currículos padronizados e apostilados, às avaliações externas, à política de bonificação na lógica da meritocracia, 
à segregação da categoria nas situações de trabalho, além das massacrantes e dispersas jornadas de trabalho (BRUNO, 2011). São situações que os imobilizam, ao produzir um quadro de dificuldades em sua atuação profissional e que não podem ser desconsideradas, a fim de não se reproduzir críticas simplistas.

Na percepção de Leandro, o ensino oferecido nem sempre o atingia e ilustra um pouco do que foi discutido anteriormente, como exemplo, ele mencionou alguns aspectos que deveriam se fazer presentes nesse processo.

O ensinamento eles davam, da forma deles, do jeito que sabiam é que explicavam [...] Vamos dizer, aquele exercício ali (mostra a lousa), eles falam é assim e assim que tem que fazer, daí as pessoas não entendem e perguntam de novo, daí eles já ficam nervosos porque terão que repetir tudo de novo [...], daí as pessoas, às vezes, ficam meio que sem entender ou com medo de perguntar para não deixá-los aborrecidos e eles ficarem maltratando, porque a gente não sai de casa para ficar ouvindo desaforos de ninguém né? Nisso a gente não perguntava e ficava sem entender [...] Nossa eu matava aulas lá heim! Nunca fui um bom aluno ali. (Participante da pesquisa).

Os vínculos positivos que teve na escola foram com a vice-diretora e um professor de Geografia. A vice-diretora dialogava bastante com ele, aliado ao fato de sempre o aconselhar. Por vez, o professor de Geografia era tido como alguém muito próximo dos estudantes, ao contribuir para que eles tivessem confiança em seus ensinamentos frente à cordialidade estabelecida na relação professor $\mathrm{X}$ aluno.

Havia uma vice-diretora que eu gostava dela [...] Porque ela sempre me entendia, ela falava assim "Oh Le, eu acho que você não precisa", porque ela via que eu ia muito pela cabeça dos outros, "Le, por que você fica aqui? Vai lá para o EJA". Porque ela sabia que com pessoas mais velhas eu não faria coisas erradas, eu iria fazer a coisa certa. Antes de acontecer (ato infracional) ela sempre me dava conselhos para eu não fazer essas coisas. Ela sabia de tudo que acontecia dentro da escola comigo, porque ela sempre ficava do meu lado, mesmo quando eu estava errado, vamos dizer que ela sabia que eu poderia ser expulso ou meio dispensado muito tempo (suspensão), ela sempre dava uma acobertada da situação, por mim, para não me prejudicar. (Participante da pesquisa).

Ah tinha um professor de Geografia chamado Anésio. Ele era um cara da hora, conversava com a gente como amigo mesmo, como colega [...]. Ele era assim, mais liberal com a gente. Se fosse para falar na gíria falava. A gente gostava mais dele [...] Ele conversava de uma forma que a gente poderia entender, explicando bem certinho palavra por palavra. Ah essa palavra aqui, por exemplo, vamos dizer ela começou no ano tal e que foi descoberta no ano tal. Ele explicava certinho para a gente saber a que ela serviu. (Participante da pesquisa).

Em oposição, Leandro mencionou a figura do diretor e de um professor de Matemática. O primeiro assumia uma postura punitiva e não dialogava com os estudantes. Por vez, o professor não aceitava a ideia dos estudantes não entenderem suas explicações, o que dificultava, inclusive, qualquer possibilidade dos mesmos sanarem suas dúvidas.

Silva e Salles (2011) apontam para uma ambivalência na relação dos adolescentes com seus professores e demais funcionários das instituições escolares. Às vezes, são relacionamentos tidos como desrespeitosos, mesmo que eles se culpem pelas dificuldades de interagir com esses profissionais, já que, como mencionam, fazem bagunça ou não são bons.

Complementando tais análises, Bazon, Silva e Ferrari (2013) explicitam que os adolescentes que têm uma trajetória positiva no início da educação escolar e que posteriormente vão experienciando o inverso, justificam a degradação da relação com os professores como um dos principais elementos desse processo. Na perspectiva desses adolescentes, os professores passam a ter certo distanciamento/frieza no modo de interagir, descompromisso ou disponibilidade para ensinar.

Ah o diretor, era mais bravo. Ah se ele pegasse fazendo algo de errado, já dava suspensão e 
mandava embora [...] Poderia agir mais educadamente. Olha não pode fazer isso! Poderia conversar primeiro! (Participante da pesquisa).

Aquele que eu falei que era nervoso, caso tivesse que repetir alguma coisa [...] Se você pedisse explicação para ele, já ficava nervoso porque achava que você não estava prestando atenção. Era de Matemática! (Participante da pesquisa).

Outro aspecto negativo a destacar, conforme a percepção de Leandro refere-se à escassez de materiais didáticos para o bom funcionamento das aulas.

Às vezes faltavam livros [...] Dicionários mesmo, não havia para todos, então tínhamos que dividir. A gente tinha que fazer em grupos já que não tinha. (Participante da pesquisa).

As escolas públicas vêm experienciandoà redução de investimentos nas últimas décadas, desencadeando maior precarização dos espaços escolares. Arelaro (2005) já sintetizava a necessidade de uma reforma tributária no país, visto que a distribuição de recursos entre as esferas públicas e os contribuintes é desigual. As regiões mais ricas concentram maior arrecadação de impostos. "A repercussão desse desequilíbrio econômico-financeiro entre os entes públicos se faz sentir na área educacional, especialmente quando se discutem as possibilidades efetivas de se construir uma escola pública "decente", em termos de qualidade de atendimento" (ARELARO, 2005, p. 1045).

Prossegue a autora, ao assumir explicitamente os modelos neoliberais, a partir de vários acordos internacionais, na década de 1990, o Brasil ao longo dos anos vem ampliando o aumento do número de alunos matriculados em escolas, independente das condições de financiamento. Nessa lógica, o discurso oficial apregoa que os recursos são suficientes, sendo apenas mal gastos e um problema gerencial.

Para além desses aspectos, há que se ponderar, ainda, que as escolas em sua maioria relegam aos estudantes as possibilidades para que tenham acesso aos saberes escolares, organizados a partir do saber sistematizado, ou seja, frente ao conhecimento humano produzido historicamente em suas diferentes dimensões (científica, filosófica e artística) (DUARTE, 2015). Tais aspectos favoreceriam, inclusive, que os estudantes pudessem compreender a realidade na qual se encontram inseridos, bem como a si mesmos.

Tais apontamentos reforçam, de acordo com Duarte (2015, p. 14), "a importância do trabalho educativo em direção à conquista de níveis cada vez mais elevados de elaboração consciente da concepção de mundo" dos estudantes. Dois são os aspectos que impactam diretamente a concepção de mundo de um indivíduo, ou seja, os seus vínculos com a luta ideológica e seu caráter constante de transformação. Todavia, nenhum indivíduo elabora sua visão de mundo do nada ou apenas a partir de suas experiências individuais. "Por mais inovadora e até revolucionária que possa ser a concepção de mundo de um determinado indivíduo, ela sempre será expressão de sua inserção no curso da história humana, com suas contradições, seus conflitos, seus dramas e seus limites" (DUARTE, 2015, p. 15).

No que tange a dimensão artística do conhecimento, são escassos os eventos culturais ou o acesso às manifestações artísticas na educação escolar. Leandro ao mencionar as atividades desenvolvidas na escola B e que abarcam tal dimensão, apresentou uma visão naturalizada da instituição, além de reforçar o quanto tais experiências são pontuais e isoladas.

Ah o interclasses né! Festa de Halloween que teve uma vez [...] a festa junina, sempre tinham esses daí [...] Ah foi legal, mas às vezes tinham muitas brigas na escola também. Mas a escola é isso mesmo! (Participante da pesquisa).

Infere-se que as dificuldades dos estudantes ao não saberem como se portar nos eventos culturais é compreensível tendo em vista o seu caráter esporádico em suas trajetórias escolares. Ressalta-se a partir de Martins (2001), que no capitalismo as objetivações humanas (produção material, linguagem, ciência, artes etc.) que oferecem possibilidades concretas para a humanização 
dos homens, não são apropriadas por todos. Para exemplificar esse processo, apresentam-se abaixo algumas palavras ditas por Leandro sobre o ínfimo contato com as manifestações artísticas em todos os seus anos de escolaridade, até o presente momento.

Uma vez nós fomos ao Salão do Livro que fica no IBC que é próximo a escola. Isso, na escola B. Era só descer a rua ao lado que estava ali atrás (da escola) [...] Uma vez fomos para um museu, ali perto do shopping [...] isso foi com a escolinha $A$. (Participante da pesquisa).

Quando questionado se ele e seus colegas de escola poderiam ter tido contato com mais lugares, mencionou outros espaços culturais da cidade.

Ah poderia! Matarazzo (centro de atividades culturais) é pertinho [...] Lá tem teatro, esses negócios, cinema [...] Não, eram só mais aulas, de Arte mesmo era só desenho e, às vezes, livrinho para responder as perguntas (caderno do aluno - proposta do Estado de São Paulo). A escola era fraca, fraquinha né? (Participante da pesquisa).

Costa et al. (2011) apontam que as dimensões artísticas para além dos espaços de educação formal, também deveriam ser utilizadas no contexto das medidas socioeducativas de internação de adolescentes autores de atos infracionais. As justificativas centram-se na defesa de que se deve compreender e intervir nas múltiplas relações que envolvem esses adolescentes. Ao resgatar a capacidade criativa, pode-se favorecer, por conseguinte, que esses indivíduos desenvolvam uma nova relação consigo mesmo e com o social.

Ao referir-se sobre os motivos para as reprovas na escola $B$, o participante destacou que era muito influenciado pelos colegas de turma.

Ah, minhas amizades eram pesadas [...] Porque quando eu estudava lá, eu acho que ia muito pela cabeça dos outros [...] Por exemplo, ah vamos "matar aula" e, eu já ia no impulso! (Participante da pesquisa).

Foi à época que estudava na escola $\mathrm{B}$ que Leandro foi pego pela polícia e encaminhado para à Fundação Casa na capital do Estado de São Paulo. Ao abordar o envolvimento de adolescentes com a prática de delitos, Bazon, Silva e Ferrari (2013, p. 179) destacam que esse é um problema que se desenvolve, a partir da vinculação do indivíduo "com seu entorno e, como demonstrado até então, a escola é uma das instâncias em que as interações estabelecidas têm importante participação na construção das trajetórias."

No que tange às experiências escolares do participante na Fundação Casa, evidenciam-se relações permeadas pelo autoritarismo, cerceamento e a ausência de liberdade para que os adolescentes pudessem dialogar durante o processo de ensino e aprendizagem.

[...] Na hora da aula era hora da aula e todo mundo ia estudar [...]. Eu estudava só na $8^{a}$ série porque eu havia reprovado [...]. Lá era rigoroso, não podia haver muita conversa. Sim, você não podia ficar com conversas, por exemplo, ficar assim: e aí colega o que você fez hoje? Porque eles achariam que você estava conversando sobre outras coisas que não tinham sentido e que você poderia trazer problemas para alguém, porque a gente estava ali cumprindo uma pena de algo errado [...]. Não tinha muita conversa entre os meninos. A escola era quieta, um silêncio total [...]. Eu não gostei pelo tempo que eu fiquei. (Participante da pesquisa).

Padovani e Ristum (2013) apontam para a necessidade de uma reflexão mais densa sobre a precariedade da instituição escolar dentro dos sistemas socioeducativos, sendo que elas não apresentam um projeto político-pedagógico que considere as especificidades e necessidades dos jovens em privação de liberdade. Há que se efetivar uma maior interação com o ambiente externo à instituição, no intuito de formar redes que auxiliem esses indivíduos não apenas enquanto privados de liberdade sob a custódia do Estado, mas também ao saírem do período de internação, a fim de consolidarem projetos de vida. 
Coadunando com os autores referenciados anteriormente, apresentam-se abaixo alguns aspectos da rotina diária de estudos de Leandro e seus colegas na Fundação.

Tinha que acordar e escovar os dentes. Se você quisesse podia tomar um banho, podia ficar arrumado. Ai batia umas 10 horas e tinha que ir para a escola, aí você estudava, depois batia meio dia e meia (12:30) e já era hora de almoçar. Mas primeiro a gente tomava café umas 8:00 horas da manhã. Aí uma e meia (13:30), umas duas horas (14:00) a gente voltava para a escola e estudava mais um pouco. E quando eram umas quatro e meia (16:30) ficava um pouco sossegado [...] Aí tinha um pouco de Educação Física, às vezes, jogava uma bola ou assistia uma televisão, mas só os desenhos, tipo Bob Esponja, esses negócios, porque era gravado. Sim, era gravado, não havia canal aberto. (Participante da pesquisa).

Tais aspectos ilustram a arbitrariedade de um sistema que os impede inclusive de terem contato com as informações do mundo exterior, ao privá-los, por exemplo, do contato com programas televisivos. Toda essa dinâmica concerne, apenas, à mutilação do desenvolvimento humano. Ainda, pensando na educação escolar recebida na Fundação Casa, Leandro mencionou que nenhum professor da instituição deixou marcas em seu processo de formação, tendo em vista que não havia oportunidade de dialogarem.

Ah não, nem tive muita conversa com eles. Não tinha conversa de ficar dialogando com eles não. (Participante da pesquisa).

Uma última dimensão a ser destacada refere-se à inserção profissional desses jovens que, em sua maioria, são excluídos socialmente. Dessa forma, foi questionado se receberam algum tipo de formação para a inserção pelo mercado de trabalho. Todavia, as falas de Leandro mostram que não havia um projeto ou trabalho coeso com essa intenção. Havia apenas orientações esporádicas por parte dos profissionais que ali trabalhavam.

Tinha assim, às vezes falavam que quando tivesse o primeiro serviço, a gente teria que saber lidar com ele, ser um bom trabalhador [...] A nossa orientadora. Sempre era a orientadora que dava conselhos, às vezes, quando vinham aqueles, como posso dizer, esqueci o nome, assistente social. (Participante da pesquisa).

Faz-se necessário ressaltar a partir de Alaniz (2012) que no discurso oficial, a oferta de ensino profissionalizante em nível básico promoveria a inclusão produtiva, sobretudo, por meio da geração de trabalho e renda da população identificada como pobre, excluída dos processos produtivos e em situação de vulnerabilidade social. Contudo, há uma contraditoriedade nesse processo, pois as políticas de formação profissional de nível básico sequer oferecem condições mínimas para que se concretize um modelo de formação profissional que prepare os jovens para o contexto de trabalho que demande complexidade.

Na mesma linha de análises, Kuenzer (2006) aponta que essa lógica culmina com a pedagogia do trabalho na acumulação flexível, ou seja, sob a ótica do mercado, há um processo de exclusão da força de trabalho dos postos reestruturados, a fim de incluí-la de maneira precarizada em distintos pontos da cadeia produtiva. No que tange à perspectiva assumida pela educação, ganha relevo movimento oposto, mas que se encontra dialeticamente integrado ao anterior, sendo que por intermédio de políticas públicas em nome da democratização, expande-se a inclusão em toda a cadeia produtiva, mas em contrapartida, precarizam-se os processos educativos.

Para Kuenzer (2006, p. 903-904), por mais que as transformações ocorridas no mundo do trabalho exijam cada vez mais um aumento da educação básica de qualidade, integrada à formação profissional tecnológica, consubstanciada:

[...] no domínio intelectual da técnica como relação entre conhecimentos e competências cognitivas complexas, o que se vem oferecendo aos que vivem do trabalho se resume [...] à reprodução do conhecimento tácito, não passando de discurso a integração entre educação básica e profissional. 


\subsection{A escola atual e uma mudança de perspectiva}

Após o período de internação, Leandro foi direcionado para a escola D (atual).

Depois que eu mudei para cá é que tudo começou a ficar diferente, eu comecei a ter outra cabeça, pois aqui tem pessoas mais velhas! (Participante da pesquisa).

Chama atenção os elogios feitos pelo participante a esta última escola, sendo que ele mencionou, inclusive, uma boa relação com os seus professores.

Boa, os professores ajudam muito quando a gente precisa ou esquece e dizem: Oh não esquece! [...] Ah uma escola boa, nessa escola eu me dei melhor. Eu consegui passar de ano aqui, estou conseguindo ter boas notas, tenho boas amizades que não me levam para o caminho ruim. Porque eu acho que tem pessoas mais velhas do que eu e, às vezes, tem um pensamento mais adulto. Então, às vezes, a gente pega os exemplos deles, são bons trabalhadores. (Participante da pesquisa).

Questionado sobre o que poderia ser modificado nessa escola, Leandro apontou:

Ah não falta nada, essa escola tem de tudo. Só muda que a noite não tem Educação Física. Às vezes a gente sente falta né. Mas de boa, melhor que aqui não tem! As outras escolas eu acho que não são tão boas como aqui [...] Ah foi onde eu senti mais vontade de aprender, nas outras não [...] Na que estudei quando era criança foi boa, mas na escola B foi o momento onde eu não fui melhor [...] Sim, aqui foi onde eu comecei progredir um pouco mais [...] Lá dentro, na Fundação, as pessoas falavam que não era certo fazer coisas erradas [...] Aí eu, por que eu estou fazendo essas coisas? Até minha mãe ficou chateada comigo. Não vou fazer de novo, vou ser uma pessoa boa. Aí comecei a vir para essa escola onde me dei melhor, comecei a ter boas notas, a ver que sou um bom aluno também [...], foi onde eu pude perceber que eu tenho capacidade de ser alguém melhor. (Participante da pesquisa).

Embora não seja foco de análise deste artigo, destaca-se que a referida instituição apresenta, regionalmente, um dos piores indicadores de desempenho nas avaliações em larga escala realizadas pela Secretaria de Educação do estado de São Paulo. Tais aspectos denunciam a contraditoriedade dos processos avaliativos, bem como que a referida instituição tem auxiliado esse adolescente a obter um fortalecimento identitário perante a vida.

Para exemplificar o rendimento satisfatório do estudante, mencionam-se os conceitos finais para cada componente curricular ao final do ano de 2014 (Arte 8,0; Biologia 10,0; Filosofia 6,0; Física 6,0; Geografia 9,0; História 6,0; Inglês 6,0; Língua Portuguesa e Literatura 6,0; Matemática 7,0; Química 7,0 e Sociologia 9,0). Mesmo que as notas, olhadas isoladamente, não sejam capazes de expressar a dimensão qualitativa do processo de ensino e aprendizagem, pondera-se que ele obteve conceitos acima da média em todas as disciplinas.

Durante o grupo focal realizado com as professoras e a coordenadora pedagógica da escola, suas falas confirmaram o que Leandro já havia relatado sobre a presença da dimensão afetiva na relação professor-alunos. De maneira geral, ao referirem-se sobre a inserção de adolescentes autores de atos infracionais que cumpriram medidas de internação no sistema regular de ensino, bem como a postura adotada pela escola e na práxis-pedagógica de cada docente, elas mencionaram, por exemplo, que:

Quando vejo que há um aluno que passou por isso, eu já chego com carinho, conversando[...] dando aquela atenção. A partir disso, eles passam a agir diferente conosco. Nós achamos que nossa escola seja bem diferenciada [...] Eles gostam da gente. Aqui nunca falamos você não vai dar em nada. (Professora 6).

Nós temos um trabalho bom! Eles gostam da gente! (Professora 3).

Além disso, enfatizaram a necessidade de preservar a identidade desses alunos quando eles regressam do regime de internação, embora muitos revelem para os professores e colegas de classe sua antiga situação. A fala da professora 2 ilustra esse processo: 
Embora a escola não divulgue quem sejam esses alunos, eu particularmente sei quem são todos. Eu sou de conversar muito com os alunos. No primeiro dia, quando chegam, eu converso no geral. Mas, depois que passo alguma atividade, vou conversando um por um [...] Eu vou bem próxima, converso com ele, sei onde ele mora, vou conhecendo um pouco mais sobre seu contexto [...] Dou a liberdade para que cheguem e contem o que for preciso [...] Eu tento ajudá-los. É uma relação de cumplicidade. Eu consigo isso. De repente, eu falo a linguagem deles, eu chego até eles. Por isso que há essa cumplicidade. (Professora 2).

A dimensão afetiva parece ser o guia da condução do trabalho docente, o que merece ser valorizado (BAZON; SILVA; FERRARI, 2013). Em um ambiente educacional onde a relação professor-aluno seja balizada pelo diálogo e respeito, o processo educativo tem mais chances de se concretizar (TASSONI; LEITE, 2011, 2013).

Todavia, um movimento mais amplo é necessário, a fim de que essas docentes e a coordenadora pedagógica possam vislumbrar um processo de humanização desses jovens, por meio do qual eles possam ser reconhecidos como protagonistas de sua história. Há que se garantir uma escola pública, revolucionária e de qualidade, que tenha como foco a transformação da sociedade geradora e produtora de todo o contexto aqui denunciado.

Conforme Costa et al. (2011), para que os adolescentes possam protagonizar suas histórias, é importante que as atividades educativas rompam com modelos verticalizados. Caso contrário, essas atividades serão, apenas, utilizadas para preencher o tempo dos jovens.

Embora tenham um senso de positividade frente às ações desenvolvidas pela escola e pelo grupo de professores, elas também reconheceram suas limitações e as dificuldades do trabalho com populações expostas a diferentes fatores de risco, já que em sua formação inicial não foram contempladas com questões desse teor.

O juiz vai mandando, manda um, manda outro. E manda todo mundo. Numa reunião na Diretoria de Ensino, justificaram que nós temos perfil para receber a EJA, alunos em L.A. Ou seja, as outras escolas não querem, daí jogam aqui. É claro que a gente acolhe! Tentamos fazer algo diferenciado, embora não signifique que a gente sempre consiga. (Coordenadora pedagógica).

Eles são muito carentes. Acho muito difícil trabalhar com esse tipo de alunos. A gente não está preparada para isso. (Professora 6).

Leandro mencionou, ainda, o exemplo de uma professora que sempre ficará em sua lembrança, por ser atenciosa e demonstrar uma relação afetiva com os estudantes durante a sua atuação profissional.

Ah a Izabel. Porque ela é uma boa professora, pra caramba, ela sabe conversar com nós. Ela é bem divertida, ela é uma amigona nossa, ela trata a gente como se fossemos amigo dela. Ah vamos dizer assim, ela brinca com a gente, como se fosse filho dela, ela brinca assim, quando a gente fala alguma coisa errada ela corrige, oh não é assim que fala. Mesmo que você não esteja conversando com ela, aí ela ouve você falar errado, e ela, é assim e te corrige [...] De Português, é por isso que ela corrige (risos). (Participante da pesquisa).

Bazon, Silva e Ferrari (2013, p. 190) destacam que a disponibilidade de ajuda, por parte dos professores, em momentos de conflitos e dificuldades, é tida pelos adolescentes como uma forma dos educadores demonstrarem consideração e estima em relação a eles. Isso viabilizou inclusive, uma maior vinculação escolar, caracterizada por uma relação pautada no diálogo e respeito professor-alunos. A partir de Sanfelice (2010), ressalta-se a necessidade de uma escola democrática e não coercitiva, na qual se desenvolva alternativas de fortalecimento da autonomia escolar e que auxilie o pleno desenvolvimento da personalidade dos estudantes.

Inclusive, o participante foi muito claro ao destacar que tem boa relação com todos os professores, direção, coordenação da escola e uma inspetora de alunos, em específico, além dos colegas de turma. 
Nenhum precisaria mudar, todos são legais (professores). Nada para falar, porque são pessoas boas também, nunca fizeram nada de mal para mim (coordenação e direção). A Cacilda (inspetora de alunos) é da hora. Porque ela é mais assim pra frente, conhece o jovem, sabe conversar com a gente [...]. Nessa escola, os amigos que posso dizer [...] hoje são o Rodrigo, que é um menino gente boa pra caramba. [...] Há o Alexandre também, a Cris, a Karen, são pessoas gente boa [...] até os professores eu considero como meus colegas porque eles conseguem conversar com a gente, sabem nos tratar de maneira correta. (Participante da pesquisa).

É notório que os elos de amizade construídos na atual escola por Leandro, junto de seus professores, funcionários e colegas são significativos. Esse é um aspecto um pouco incomum, pois a maioria dos jovens quando saem do regime de internação apresentam grandes dificuldades de se sentirem bem nas escolas onde são inseridos, seja por serem rotulados, por preconceito de seus pares e professores ou até mesmo pela insegurança em novos espaços de socialização (FEFFERMANN, 2008; MONDINI, 2011). Bazon, Silva e Ferrari (2013, p. 180) salientam a necessidade de se "estudar como tais processos ocorrem, verificando quais aspectos escolares podem influenciar o comportamento do jovem, além de compreender como esse os vivencia e percebe."

Toda essa repercussão positiva fez com que Leandro começasse a almejar projetos futuros para sua vida. Silva e Salles (2011) ao abordarem a percepção dos participantes de sua investigação sobre a escola esclarecem que a escola para eles é percebida somente na relação com a vida futura, sobretudo diante da possibilidade de conseguirem um bom emprego e permitir o ingresso no ensino superior. Infelizmente a escola não é entendida como um espaço que contribui para sua formação pessoal, cultural, social e política. Dessa forma impera uma visão utilitarista da escola, como se fosse apenas uma instância de certificação.

Há que se destacar que as expectativas do participante, ainda, são muito escassas do ponto de vista de estarem circunscritas apenas a lógica de ter uma casa, constituir família e obter um posto de trabalho. Em nenhum momento ele mencionou a questão de poder viajar, ter acesso à arte ou a cultura, dimensões que sempre foram secundarizadas em sua vida e que ainda não são vistas como prioridade.

A partir de Castro e Guareschi (2008) infere-se que a subjetivação de um indivíduo deve ser entendida como uma produção discursiva social e cultural, pari passu, como modos dele ser constituído e de estar no mundo.

Ah, arrumar um serviço bom, e desse serviço bom comprar uma casa, arrumar alguém e casar, depois de conquistar tudo, ter uma família. E aí, preparar a vida para criar os filhos e aí preparar a vida para Deus levar depois, pois já vou ter cumprido tudo na terra [...] Tudo né, porque você já viveu a vida inteira, quase que a vida toda, você já trabalhou, já construiu família [...] Mais nada né! Ah só isso mesmo, e permanecer com a cabeça no caminho certo pra não entrar no caminho errado. (Participante da pesquisa, 2014).

No que tange as expectativas futuras de inserção profissional, Leandro mencionou a vontade de cursar uma faculdade, embora tenha uma visão muito simplista do curso almejado, mas que pode ser um retrato do que foi oferecido pelas escolas por onde passou.

Posso dizer que sim, um dia uma faculdade. Ah não sei, talvez Educação Física. É para ser professor de Educação Física. Porque não faz nada, só dá aulas de futebol, essas coisas [...] Eu acho (risos). (Participante da pesquisa).

Há que se registrar, ainda, que após a internação ele não foi direcionado para nenhum projeto social, apenas o conduziram para assistir algumas palestras que debatiam o tema da drogadição na vida dos jovens. Posterior a sua saída, ele começou a fazer um curso técnico numa escola do Serviço Nacional de Aprendizagem Industrial (SENAI).

Eu fiz um de oficial administrativo. Fiz no começo de maio e fui terminar agora em julho (2014). 
Fiz no SENAI mesmo, pelo PRONATEC [...] Eu achei muito legal, gostoso pra caramba. Gostei também porque eu fiz amizades, aprendi sobre outras coisas [...] o que era mexer com papel; mexer com formulários, essas coisas que eu não sabia o que era [...] Ah foi muito construtivo, conseguiu colocar minha cabeça em ordem. Ah porque eu já não tinha mais o pensamento de antes [...] Antes de acontecer o que aconteceu comigo que estava na vida louca (tráfico de drogas). Entendeu? Olha saiu de lá do meio da biqueira (ponto de comercialização das drogas) e agora tá lá fazendo um curso! (Participante da pesquisa).

Embora Leandro tenha uma visão positiva do curso, ressalta-se a partir de Alaniz (2012) e Kuenzer (2006) a forma superficial e aligeirada que esses cursos vêm sendo ofertados. Acrescenta-se o fato de muitas vezes estarem desvinculados da educação básica de qualidade e apresentarem propostas demagógicas, além de reforçarem "o consumo predatório da força de trabalho ao longo das cadeias produtivas" (KUENZER, 2006, p. 904).

Para Marx (2006) e Marx e Engels (1974), ao longo do desenvolvimento histórico vem ocorrendo um processo de transformação na consciência humana, em decorrência das condições de desenvolvimento da divisão social do trabalho. A expropriação econômica suscitada pela iniciativa privada conduz a alienação, a desintegração da consciência das pessoas. Nesse sentido, o pensamento e a consciência são determinados pela vida real, por intermédio das relações objetivas presentes na vida de um indivíduo (LEONTIEV, 1983).

Tais aspectos evidenciam a necessidade de procedimentos pedagógicos que assegurem aos estudantes "o exercício da crítica, da criação, da participação política ou do acesso aos conhecimentos necessários para enfrentar os desafios de uma sociedade cada vez mais excludente" (KUENZER, 2006, p. 904), a fim de que o domínio dos conhecimentos científicos, filosóficos, artísticos, tecnológicos e sócio históricos garanta a formação de um indivíduo com autonomia intelectual e ética (DUARTE, 2015; KUENZER, 2006).

\section{4 | PARA FINALIZAR}

A pesquisa no formato de estudo de caso, não pode ser generalizada, embora traga aspectos e indicativos que estão circunscritos ao modelo de organização social capitalista, ou seja, que se fazem presentes na vida de parcela expressiva da população.

No que tange à inserção escolar na vida do participante, constatou-se a importância da escola atual ao recebê-lo após o período da internação para cumprimento de medida socioeducativa na Fundação Casa. Em seus depoimentos ficou evidente, por parte da escola, uma postura de acolhida, permeada por uma dimensão afetiva muito intensa, sobretudo, por parte dos docentes e funcionários que não rotulam os estudantes e/ou evitam comparações caso tenham cometido algum ato infracional. Essa dinâmica institucional foi positiva, ao fazer com que ele se sentisse confiante e percebesse a necessidade de terminar os estudos, a fim de obter futura inserção profissional, além de almejar o ingresso na universidade.

Contudo, há uma contraditoriedade nesse processo, pois por mais que esse adolescente tenha permanecido e se sentido acolhido nas atividades escolares, sua situação não é regra, tendo em vista que vários outros alunos evadiram da escola. Tal cenário põe em evidência a ausência de recursos ou programas sociais que deveriam ser capazes de reinseri-los qualitativamente na sociedade, bem como o preconceito presente na sociedade que os culpabiliza como os únicos responsáveis por seus atos e atitudes. 


\section{Referências}

ALANIZ, E. P. A política pública de formação para economia solidária no Brasil (2003-2011): análise de um projeto PROESQ/PNQ executado pela Rede Abelha/RN e do CFES nacional. 2012. 371 f. Tese (Doutorado em Educação) - Faculdade de Educação, Universidade de São Paulo, São Paulo, 2012.

ARELARO, L. R. G. O ensino fundamental no Brasil: avanços, perplexidades e tendências. Educação \& Sociedade, Campinas, v. 26, n. 92, p. 1039-1066, out. 2005.

BAZON, M. R.; SILVA, J. L.; FERRARI, R. M. Trajetórias de adolescentes em conflito com a lei. Educação em Revista, Belo Horizonte, v. 29, n. 2, p. 175-199, jun. 2013.

BRASIL. Lei n 8.069 , de 13 de julho de 1990. Dispõe sobre o Estatuto da Criança e do Adolescente e dá outras providências. Diário Oficial da União. Brasília, DF, 16 jul. 1990.

BRUNO, L. Educação e desenvolvimento econômico no Brasil. Revista Brasileira de Educação, Rio de Janeiro, v. 16, n. 48, p. 545-562, set./dez. 2011.

CAMACHO, V. A. L. Problematizando mudanças espaciais e temporais entre os censos de 2000 e 2010: os mapas da exclusão/inclusão social de Presidente Prudente/SP. 2013. 91 f. Monografia (Bacharelado em Geografia) - Faculdade de Ciências e Tecnologia, Universidade Estadual Paulista, Presidente Prudente, 2013.

CASTRO, A. L. S.; GUARESCHI, P. Da privação da dignidade social à privação da liberdade individual. Psicologia \& Sociedade, Belo Horizonte, v. 20, n. 2, p. 200-207, maio/ ago. 2008.

COELHO, B. I.; ROSA, E. M. Ato infracioal e medida socioeducativa: representações de adolescentes em L.A. Psicologia \& Sociedade, Belo Horizonte, v. 25, n. 1, p. 163173, jan./abr. 2013.

COSTA, C. R. B. S. F. et al. Música e transformação no contexto da medida socioeducativa de internação. Psicologia: ciência e profissão, Brasília, v. 31, n. 4, p. 840-855, out./dez. 2011.

DUARTE, N. A importância da concepção de mundo para a educação escolar: porque a pedagogia histórico-crítica não endossa o silêncio de Wittgenstein. Germinal: Marxismo e Educação em Debate, Salvador, v. 7, n. 1, p. 8-25, jun. 2015.

FEFFERMANN, M. O cotidiano de jovens trabalhadores do tráfico. Segurança Urbana e juventude, Araraquara, v. 1, n. 2, p. 01-14, jun./dez. 2008.

HADDAD, S. Introdução. In: Banco Mundial, OMC e FMI: o impacto nas políticas educacionais. São Paulo: Cortez, 2008. p.7-14.

KUENZER, A. Z. A Educação profissional nos anos 2000: a dimensão subordinada nas políticas de inclusão. Educação \& Sociedade, Campinas, v. 27, n. 96, p. 877-910, out. 2006.
LEONTIEV, A. N. Actividad, conciencia, personalidad. 2. reimpresión. La Habana: Editorial Pueblo y Educación, 1983. 249 p.

MARTINS, L. M. Análise sócio-histórica do processo de personalização de professores. 2001. 194 f. Tese (Doutorado em Educação) - Faculdade de Filosofia e Ciências, Universidade Estadual Paulista, Marília, 2001.

MARX, K. Trabalho assalariado e capital \& Salário, preço e lucro. São Paulo: Expressão Popular, 2006.

MARX, K; ENGELS, F. A ideologia alemã. 11. ed. São Paulo: Martins Fontes, 1974.

MONDINI, C. E. C. M. Resiliência e medidas socioeducativas: síntese dialética de múltiplas determinações. 2011. 220 f. Dissertação (Mestrado em Educação) - Universidade Federal do Mato Grosso do Sul, Corumbá, 2011.

PADOVANI, A. S.; RISTUM, M. A escola como caminho socioeducativo para adolescentes privados de liberdade. Educação e Pesquisa, São Paulo, v. 39, n. 4, p. 969-984, out./dez. 2013.

PAULO NETTO, J. Introdução ao estudo do método de Marx. São Paulo: Expressão Popular, 2011.

SALDOMBIDE, S. C. G. Libertad vigilada: un estudio sobre las tecnologías de gobierno. Psicologia \& Sociedade, Belo Horizonte, v. 25, n. 2, p. 362-371, maio/ago. 2013.

SANFELICE, J. L. A política educacional do estado de São Paulo: apontamentos. Nuances: estudos sobre educação, Presidente Prudente, v. 17, n. 18, p. 145-159, jan./ dez. 2010.

SILVA, R. B. A segregação socioespacial urbana em Presidente Prudente-SP. Revista da Católica, Uberlândia, v. 1, n. 2, p. 81-104, maio/ago. 2009.

SILVA, I. R. O.; SALLES, L. M. F. Adolescentes em liberdade assistida e a escola. Estudos de Psicologia, Campinas, v. 28, n. 3, p. 353-362, jul./set. 2011.

TASSONI, E. C. M.; LEITE, S. A. S. Afetividade no processo de ensino-aprendizagem: as contribuições da teoria walloniana. Educação (PUCRS), Porto Alegre, v. 36, n. 2, p. 262-271, maio/ago. 2013.

Um estudo sobre emoções e sentimentos na aprendizagem escolar. Comunicações, Piracicaba, v. 18, p. 79-91, 2011.

VYGOTSKI, L. S. La tragedia de Hamlet \& Psicología del arte. Madrid: Fundación Infancia y Aprendizaje, 2007. 371 p.

VYGOTSKY, L. S. Obras escogidas III: Problemas del desarrollo de la psique. Madrid: Visor, 1995. 383 p. 